\title{
GATA3 frameshift mutation promotes tumor growth in human luminal breast cancer cells and induces transcriptional changes seen in primary GATA3 mutant breast cancers
}

\author{
John P. Gustin ${ }^{1}$, Jernelle Miller ${ }^{1}$, Mina Farag ${ }^{1}$, D. Marc Rosen ${ }^{1}$, Matthew Thomas ${ }^{1}$, \\ Robert B. Scharpf ${ }^{1}$ and Josh Lauring ${ }^{1}$ \\ ${ }^{1}$ Sidney Kimmel Comprehensive Cancer Center at Johns Hopkins, Baltimore, MD, USA
}

Correspondence to: Josh Lauring, email: jlauring@jhmi.edu

Keywords: GATA3, mutation, breast cancer, luminal

Received: October 05, 2017 Accepted: October 10, $2017 \quad$ Published: October 20, 2017

Copyright: Gustin et al. This is an open-access article distributed under the terms of the Creative Commons Attribution License 3.0 (CC BY 3.0), which permits unrestricted use, distribution, and reproduction in any medium, provided the original author and source are credited.

\section{ABSTRACT}

The GATA3 transcription factor is one of the most frequently mutated genes in breast cancer. Heterozygous mutations, mostly frameshifts, are seen in $15 \%$ of estrogen receptor positive breast cancers, the subtype in which these mutations are almost exclusively found. Mouse studies have shown that Gata3 is critical for breast development and that GATA3 gene dosage affects breast tumor progression. Human patient data have shown that high Gata3 expression, a feature of luminal subtype breast cancers, is associated with a better prognosis. Although the frequency of GATA3 mutation suggests an important role in breast cancer development or progression, there is little understanding of how mutations in GATA3 affect its function in luminal breast epithelial cells and what gene expression changes result as a consequence of the mutations. Here, using gene editing, we have created two sets of isogenic human luminal breast cancer cell lines with and without a hotspot truncating GATA3 mutation. GATA3 mutation enhanced tumor growth in vivo but did not affect sensitivity to clinically used hormonal therapies or chemotherapeutic agents. We identified genes with upregulated and downregulated expression in GATA3 mutant cells, a subset of which was concordantly differentially expressed in GATA3 mutant primary luminal breast cancers. Addback of mutant GATA3 recapitulated mutation-specific gene expression changes and enhanced soft agar colony formation, suggesting a gain of function for the mutant protein.

\section{INTRODUCTION}

Heterozygous mutations in the GATA3 gene, encoding a transcription factor crucial for breast development, occur in $15 \%$ of estrogen receptor-positive $(\mathrm{ER}+)$, or luminal-type, breast cancers [1, 2]. Mutations in GATA3 are heterogeneous, but almost all of the mutations affect splice sites or are insertions/deletions (indels) that result in translational frameshifts. Many of these mutations result in premature termination of translation and truncated proteins lacking all or part of the second zinc finger, which mediates DNA binding [3]. Another cluster of mutations occurs near the C-terminus of Gata3, and it is not clear whether these mutations affect Gata3 function in the same manner as truncating mutations.
Some of the breast cancer-associated truncating mutations cluster in the same region as mutations in the HDR syndrome (hypoparathyroidism, sensorineural deafness, and renal insufficiency), an autosomal dominant disorder ascribed to Gata3 haploinsufficiency [4]. However, mutant GATA3 transcripts and proteins are highly expressed, and the mutational bias toward the distal part of the protein suggests that these mutations do not cause a simple loss of function.

Gata3 expression is highest in hormone receptorpositive breast cancers. Several studies have shown that Gata3 expression correlates with a better prognosis, which is not surprising given the tight correlation between Gata3 expression and ER expression (>90\% co-expression) [5-9]. Since GATA3 mutations in most cases examined 
do not lead to loss of transcript or protein, they are not identified by prognostic studies using gene expression microarrays or immunohistochemistry. The METABRIC study reported that GATA3 mutant tumors have a favorable prognosis compared to GATA3 wild type ER+ breast cancers [1]. However, the prevalence of GATA3 mutations in a population of treatment refractory metastatic breast cancers was identical to that reported in primary tumors $(12 \%)$, suggesting that GATA3 mutant tumors are not especially favorable [10].

Studies using human breast cancer cell lines show that Gata3 co-regulates certain genes with the estrogen receptor alpha $(\mathrm{ER} \alpha)$ and that there may be reciprocal regulation between Gata3 and $\operatorname{ER} \alpha[11,12]$. A gene expression signature enriched for genes induced by both estrogen and Gata3 defined a good prognosis subgroup of breast cancer patients, however Gata3-regulated genes were defined as those induced by overexpression of Gata3 in HEK-293 kidney cells, rather than in breast epithelial cells [13]. Several Gata3 target genes have been proposed, including CCND1, CDKN2C, MUC1, and ESR1 [14-16], however the target genes affected by Gata3 mutations in human breast cancers have not been elucidated.

Prior work by others has demonstrated a range of phenotypes with ectopic Gata3 overexpression or knockdown. Studies examining the effect of expressing wild type Gata3 in ER-negative cell lines such as MDAMB-231 have shown that Gata3 favors expression of epithelial over mesenchymal markers and negatively regulates breast cancer metastasis [17-21]. However, such studies, while suggestive, do not address the function of Gata3 in the luminal breast cell types where it is highly expressed and frequently mutated. Ectopic overexpression or gene knockdown do not always recapitulate the phenotypes generated by physiologic expression of cancer-associated mutations using gene editing [22-24]. Here, we have utilized gene editing in human ER+ breast cancer cell lines to identify phenotypes and transcriptional targets dependent on mutant GATA3.

\section{RESULTS}

\section{Isogenic human breast cancer cell line models to study effects of GATA3 mutations}

In order to study the functional consequences of GATA3 mutations in a human breast cancer system, we utilized the MCF-7 cell line, widely used as a representative model for $\mathrm{ER}+$, luminal-type breast cancer. MCF-7 cells have a naturally occurring GATA3 mutation, a $\mathrm{G}$ insertion in exon 5, leading to a frameshift and premature truncation of the translated polypeptide (D336Gfs*17, Figure 1) [4]. This mutation occurs in the second zinc finger of the Gata 3 protein, and such mutations have been shown to disrupt binding to GATA motifs in DNA $[3,25]$. This mutation is a recurrent hotspot in primary human breast cancers, having been reported 16 times in the TCGA and METABRIC datasets. Therefore, MCF-7 is a relevant model to understand the functional consequences of GATA3 truncating mutations that occur almost exclusively in ER+ breast cancers. We confirmed the presence of the GATA3 mutation in our MCF-7 cells by sequencing genomic DNA as well as cDNA. The mutation is heterozygous and equally expressed at the mRNA level with the wild type allele (Figure 1B). Western blotting confirmed the presence of full length and truncated forms of the Gata3 protein of the expected sizes (Figure 1D). It is interesting to note that the truncated Gata3 polypeptide is more abundant than the wild type protein, despite equal transcription, likely reflecting increased protein stability.

We designed a rAAV gene targeting vector to replace the mutant GATA3 exon 5 with a wild type copy (Figure 1A). We obtained three targeted clones. Sequencing revealed replacement of the mutant allele with wild type sequence (Figure 1B); however, as suggested by published copy number data, MCF-7 appears to have four copies of chromosome 10, with two wild type and two mutant GATA3 alleles. Thus, the first round of correction left three wild type alleles and one mutant allele. We therefore designed a second targeting construct with GATA3 exon 5 in the 3 ' homology arm, to minimize retargeting events. Two homozygous wild type GATA3 MCF-7 (hereafter referred to as GATA3 WT) clones were derived, each from an independent first-allele-targeted clone. Sequencing of genomic DNA and cDNA confirmed the complete absence of the $\mathrm{G}$ insertion mutation (Figure $1 \mathrm{~B}$ and data not shown), and western blotting demonstrated full length Gata3 protein only. GATA3 WT clones showed similar levels of full length Gata3 and ER $\alpha$ to parental MCF-7 cells (Figure 1D). Successful recovery of fully wild type GATA3 clones shows that MCF-7 cells do not require mutant Gata3 for survival.

We developed a second model using CAMA1, another ER+ breast cancer cell line, which is GATA3 wild type. We used the same gene targeting strategy to introduce the MCF-7 derived D336Gfs*17 mutation on a single allele in CAMA1 cells. Sanger sequencing shows a less than 1:1 ratio of wild type and mutant GATA3 alleles in the targeted CAMA1 clones (Figure 1C). Droplet digital PCR copy number analysis shows that the CAMA-1 cells likely have four copies of the GATA3 locus, like MCF7 (data not shown). Thus, the CAMA1 GATA3 mutant knock-in clones do not fully recapitulate the allelic ratio of MCF-7 and most primary breast cancers. Initially two mutant knock-in clones were obtained. However, the second GATA3 mutant CAMA1 clone lost expression of the mutant allele, presumably through epigenetic downregulation, since the mutant allelic ratio remained approximately 1:3 in genomic DNA, whereas the mutant transcript and protein were barely detectable by RT-PCR and western blotting (Figure 1C and 1D). This second clone was therefore used as a wild type control (hereafter 
referred to as "Control KI"), having been through the same gene editing process as the GATA3 mutant-expressing clone.

\section{Growth and drug sensitivity of $G A T A 3$ mutant and wild type cells}

In cell culture, the two GATA3 WT clones proliferated with similar kinetics to parental MCF-7 cells overall, whether grown in low-serum $(0.5 \% \mathrm{CD}-\mathrm{FBS})$ or in the presence of $17-\beta$-estradiol. Significant differences were only observed between MCF-7 and WT clone 1 in the absence of estrogen and between MCF-7 and WT clone 2 in the presence of estrogen (adjusted $p<0.01$ for each comparison, Figure 2A). GATA3 mutant knock-in CAMA1, however, grew faster compared to GATA3 wild type parental CAMA1 or control knock-in cells cells in low serum and in the presence of estrogen $(p<0.001$ for all comparisons, Figure 2B). In soft agar, parental MCF7 cells formed colonies equally well in the presence or absence of estrogen ( $P$ value non-significant), whereas both GATA3 WT clones formed significantly more colonies in the presence of estrogen (Figure 2C and 2D). Thus, GATA3 mutation appears to render MCF-7 cells less dependent on estrogen for anchorage-independent growth. Of note, GATA3 mutation did not affect the estrogeninduced downregulation of $\mathrm{ER} \alpha$, and both wild type and truncated Gata3 proteins were downregulated concordantly in response to estrogen (Figure 1D). Attempts to grow CAMA1 cells in soft agar were unsuccessful.

Because Gata3 has been implicated in the coregulation of ER target genes and because of the differential soft agar growth response in the absence of estrogen, we hypothesized that parental MCF-7 cells with mutant Gata3 would be more resistant to hormonal therapies. Cells were grown in $1 \mathrm{nM}$ estradiol and treated
A
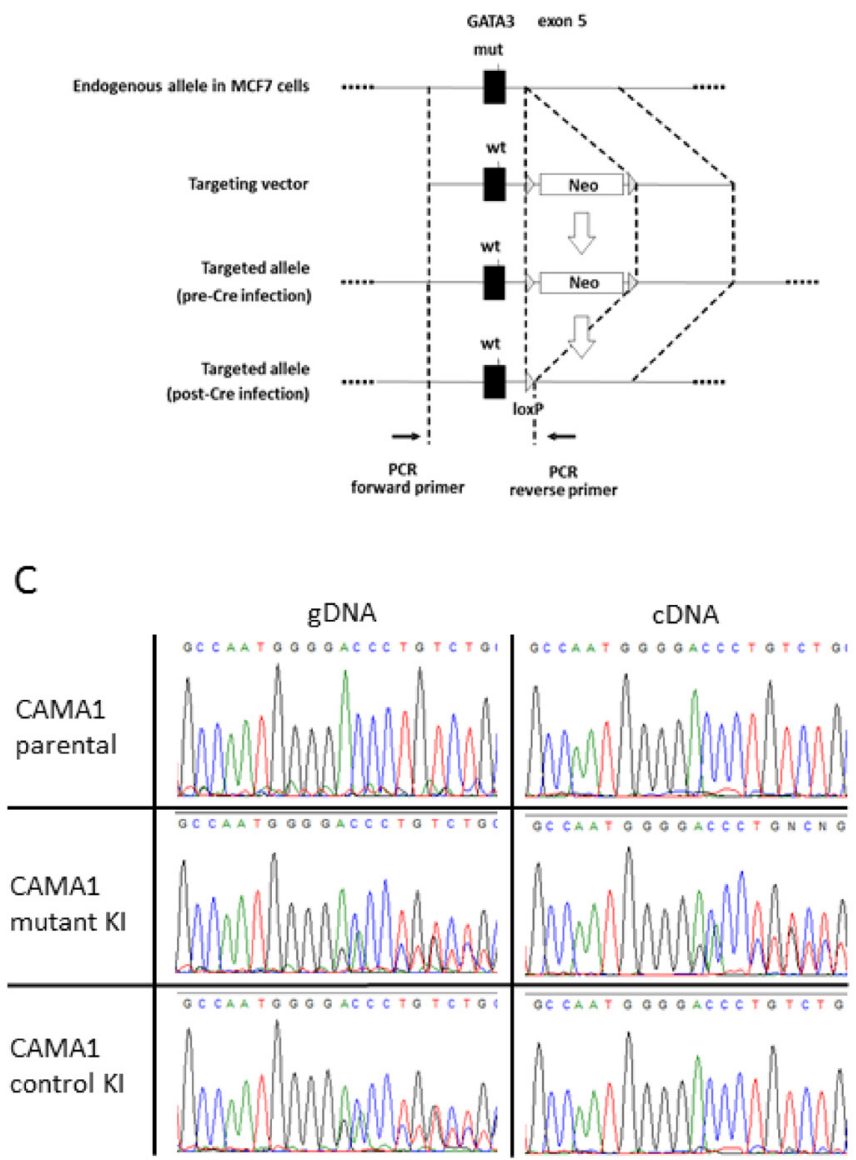

B
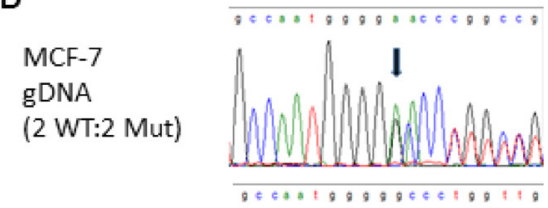

MCF-7

CDNA

Correction of $1^{\text {st }}$ allele gDNA (3 WT:1 Mut)

Correction of $2^{\text {nd }}$ allele gDNA (4 WT:0 Mut)
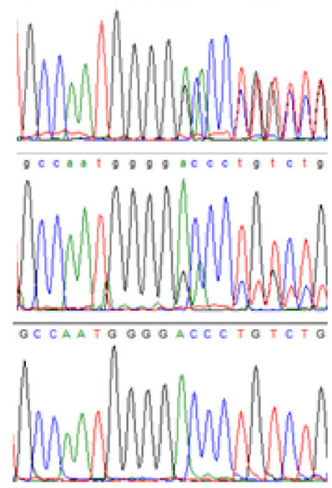

D

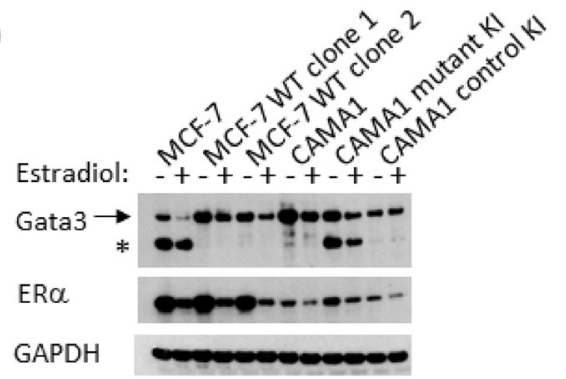

Figure 1: Correction of the GATA3 D336Gfs*17 mutation in MCF-7 and knock-in of GATA3 D336Gfs*17 in CAMA1 cells using gene targeting. (A) Schematic of the gene targeting construct used for the first allele. (B) Sequencing traces showing correction of first and second mutant GATA3 alleles in MCF-7. A single representative clone is shown for each step. Arrow indicates start of frameshift. (C) Sequencing trace of gDNA and cDNA showing knock-in of mutant GATA3 alleles in two CAMA1 clones, one of which lost expression of the mutant GATA3 transcript ("control KI"). (D) Western blot showing full length (arrow) and truncated (asterisk) Gata3 proteins in parental MCF-7 cells, two GATA3 wild type corrected clones, parental CAMA1 cells, GATA3 mutant knock-in (KI) clone, and control KI clone. Cells were cultured in the presence or absence of 17- $\beta$-estradiol. Estrogen receptor (ERa) and GAPDH proteins are shown for comparison. 
with a range of concentrations of the active metabolite 4-OH tamoxifen (Figure 3A) or the selective estrogen degrader fulvestrant (Figure 3B). There was no significant difference in the sensitivity of the cells to hormonal therapy according to GATA3 mutation status ( $p=\mathrm{ns}$ by ANOVA). The cells also exhibited similar sensitivity to the chemotherapeutic drugs doxorubicin (although the IC50 difference of $1.4 \mathrm{nM}$ was statistically significant, $p<0.0001$, Figure 3C) and paclitaxel (Figure 3D). The similar sensitivity to paclitaxel is notable, as the GATA3 mutant MCF-7 cells showed higher transcript levels of $T U B B 3$, encoding the beta 3 isoform of tubulin, which has been associated in some studies with paclitaxel resistance (Figure 4 and Supplementary Table 1) [26].

\section{Transcriptional consequences of GATA3 mutations}

Since Gata3 is a transcription factor and a master regulator of breast development, we hypothesized that GATA3 mutation would alter transcription of downstream
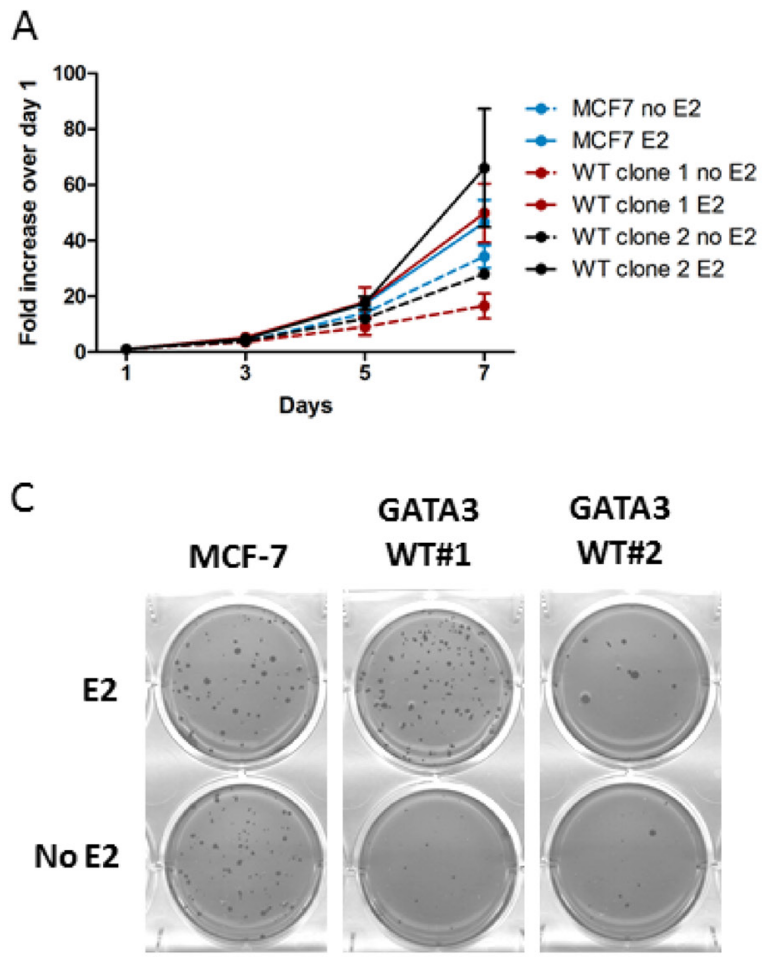

target genes. Therefore, we performed whole-genome gene expression analyses comparing MCF-7 parental and GATA3 WT cells and CAMA1 parental and GATA3 mutant cells. Four hundred forty-seven genes were differentially expressed in MCF-7 cells according to GATA3 mutation status at a Benjamini-Hochberg adjusted $p$ value of $<$ 0.05 (Supplementary Table 1). In CAMA1 cells, 993 genes were differentially expressed at 1.25 -fold or greater between parental CAMA1 and the GATA3 mutant knockin cells. Given the large number of genes in the genomic platforms and the limited replicates for each clone, we sought to identify concordantly over-expressed genes in the two cell lines, as we hypothesize that expression of bona-fide targets of GATA3 are more likely to be similarly effected in both cell lines. We defined genes with concordant differential expression in both cell lines by statistically significant moderated t (MCF-7 mutant versus wild type) and 1.25-fold change in expression (CAMA1 parental versus GATA3 mutant knock-in clone). Fifty-three genes were concordantly differentially expressed according to GATA3 mutation status between
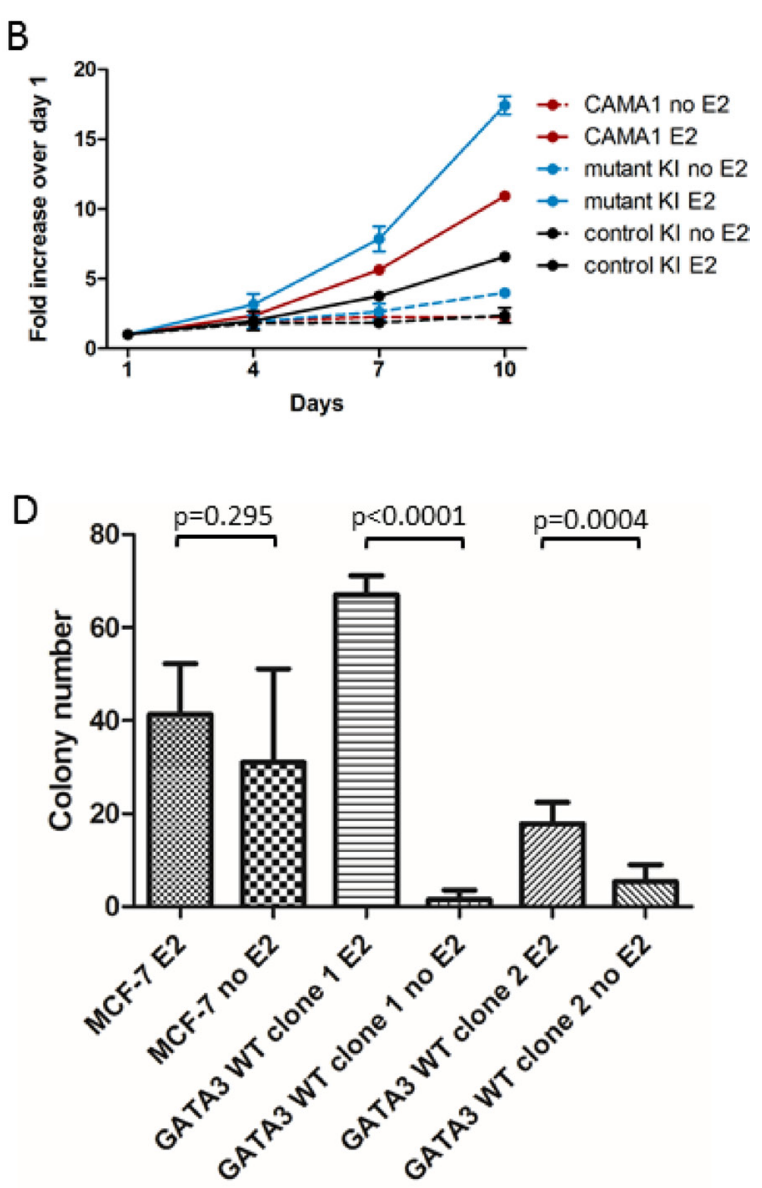

Figure 2: Growth comparison of MCF-7 and GATA3 wild type derivatives. (A) Proliferation of parental MCF-7 and GATA3 wild type derivative clones in the presence and absence of estrogen (E2). (B) Proliferation of parental CAMA1, GATA3 mutant knock-in, and control knock-in cells in the presence and absence of estrogen. (C) Colony formation in soft agar by MCF-7 and GATA3 wild type derivative clones in the presence and absence of estrogen. (D) Quantification of soft agar colonies (average of two experiments). Means and standard deviations are shown. $P$ values are from unpaired $t$-tests for the comparisons shown. 
the MCF-7 and CAMA1 cell line panels, $\left(p<7 \times 10^{-11}\right.$ by hypergeometric probability test, Figure 4 ).

In order to understand the relevance of the gene expression changes we observed in our isogenic cell lines to primary human breast cancers, we examined gene expression in the TCGA breast cancer dataset. The TCGA dataset contains 594 primary ER+ breast cancers with RNAseq and mutation data, of which 84 (14\%) have GATA3 mutations. 313 genes were differentially expressed in GATA3 mutant versus wild type cases at a BenjaminiHochberg q value of $<0.01$ (Supplementary Table 1). Of these 313 genes, 14 are concordantly differentially expressed in the MCF-7 isogenic cell lines and 24 in the CAMA1 cell lines ( $p<0.004$ and $p<0.007$, respectively, by hypergeometric probability test, Figure 4). Four genes showed concordant differential gene expression in all three datasets: CYBRD1, PPT1, LIMCH1 and TBC1D9.

Differential expression of several of these genes was verified in the MCF-7 and CAMA1 cell line panels by qRTPCR, including some interrogated genes that did not show consistent changes by microarray between the two cell lines (Figure 5). Expression of TBC1D9 and CEACAM6 was higher in GATA3 mutant MCF-7 cells, GATA3 mutant CAMA1 cells, and primary GATA3 mutant breast cancer
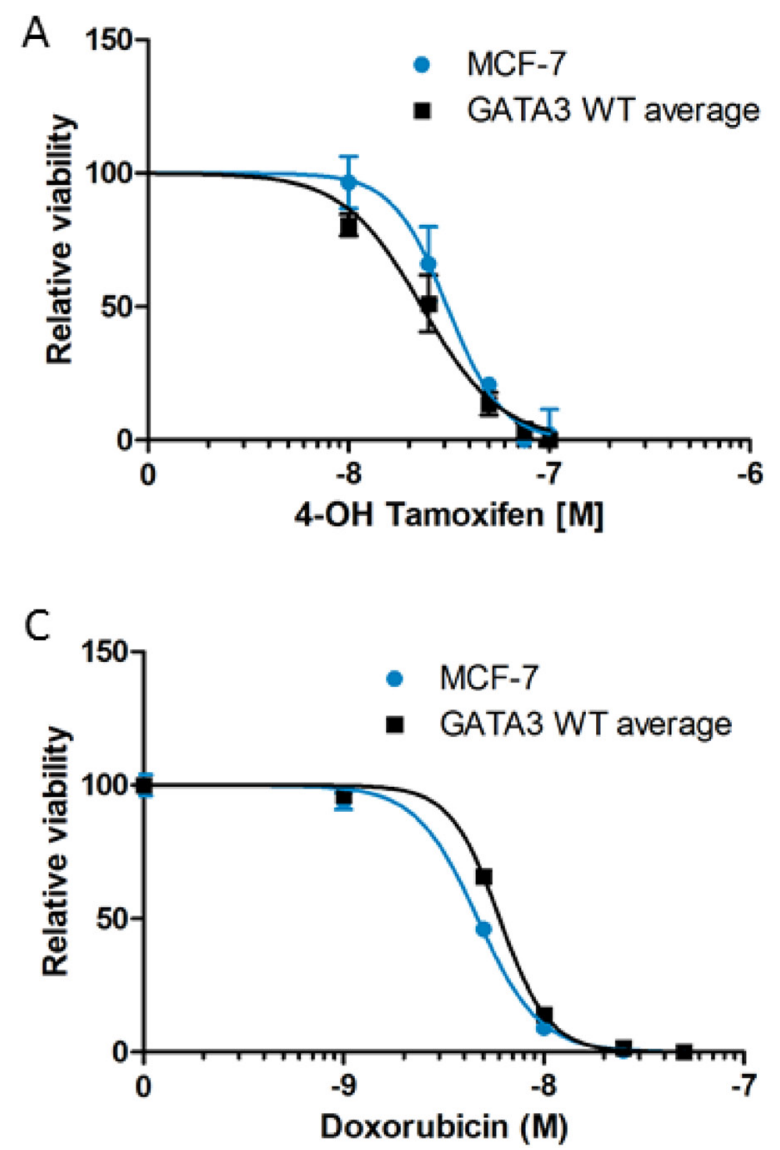

cells, whereas expression of PPT1, CYBRD1, HOXC13, and $A F F 3$ was higher in GATA3 wild type cells (Figures 4 and 5). Importantly, the gene targeting event is associated with opposite genotypes in the MCF-7 and CAMA1 cells. Therefore, the observation of concordant changes in the two different cell lines supports these being bona fide targets affected by GATA3 mutation, rather than effects of the gene targeting process. To further validate these target genes, we re-expressed the Gata3 D336Gfs*17 mutant in the two MCF7-derived GATA3 WT clones (Figure 6A). Truncated mutant Gata3 protein was expressed at a similar level to that in MCF-7 cells. Re-expression of mutant Gata3 induced gene expression changes concordant with MCF-7, suggesting that some of these changes are at least partly due to gain-offunction of the mutant protein (Figure 6B). Addback of mutant GATA3 also enhanced soft agar colony formation in both wild type clones, again consistent with a dominant gain of function for the mutant protein ( $p=0.003$ by $t$ test, Figure $6 \mathrm{C})$.

\section{Mutant Gata3 enhances breast cancer tumor growth in vivo}

Parental MCF-7 cells formed tumors in estrogensupplemented nude mice, as expected. Tumors did not
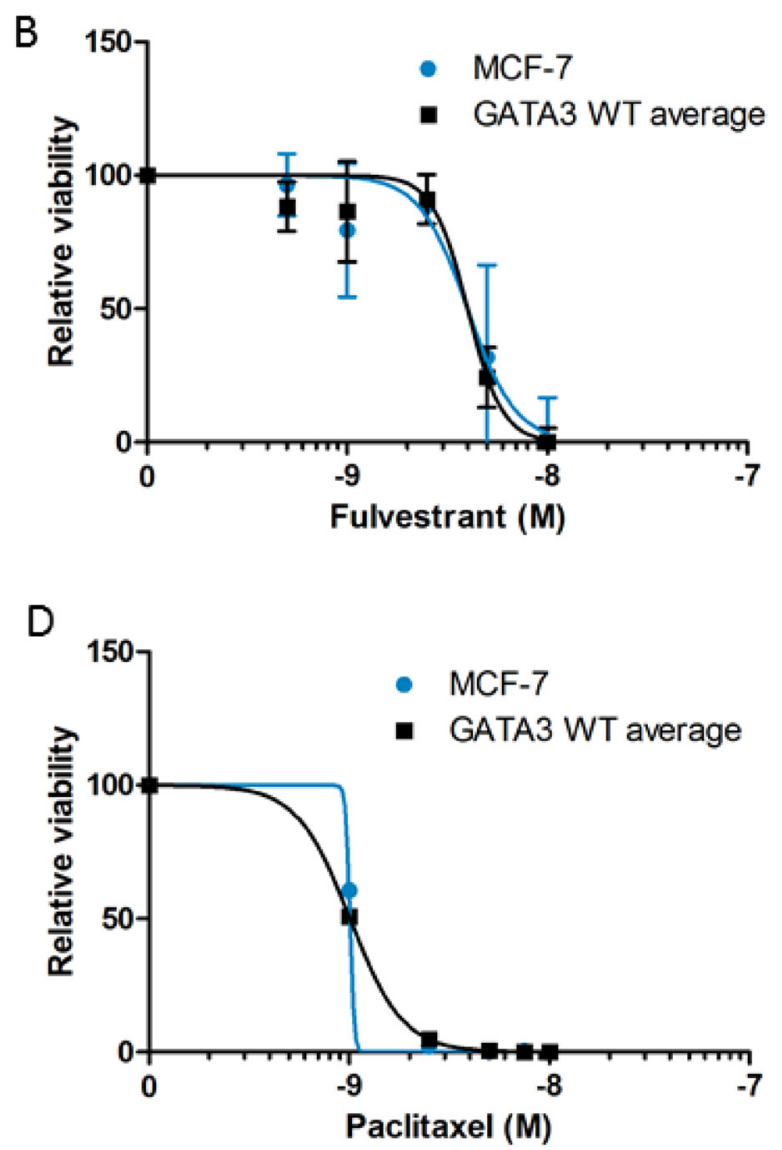

Figure 3: Drug sensitivity of MCF-7 and GATA3 wild type derivative clones to 4-OH tamoxifen (A), fulvestrant (B), doxorubicin (C), and paclitaxel (D). Cell viability relative to untreated control is shown for each cell line. Graphs depict curve fit of the data using nonlinear regression for MCF-7 versus the average of the two wild type clones. 
form in the absence of estrogen pellet implantation (data not shown), confirming that these cells had not acquired estrogen-independence. GATA3 wild type cells $(n=5$ per clone) grew significantly more slowly and formed smaller tumors compared to parental MCF-7 ( $n=9, p=0.001$ by repeated measures two-way ANOVA, Figure 7A). Parental CAMA1 cells and GATA3 wild type-expressing control knock-in cells failed to grow after orthotopic implantation in NSG mice, but the GATA3-mutant-expressing targeted clone did form tumors ( $n=10$ per group, $p<0.0001$ by repeated measures two-way ANOVA, Figure 7B). Thus, correction of mutant GATA3 back to wild type impaired estrogen-dependent growth of MCF-7 breast cancer cells in vivo, and knock-in mutant GATA3 was sufficient to confer the ability of CAMA1 cells to grow as xenografts in immunocompromised mice.

\section{DISCUSSION}

Gata3 is essential for breast development [27, 28]. Heterozygous mutations in GATA3, mostly frameshifts, occur in approximately $15 \%$ of primary ER+ human breast cancers, suggesting that Gata3 may function as a haploinsufficient tumor suppressor for luminal breast cancers. However, clustering of mutations toward the C-terminal region of the protein and continued high expression of the mutant protein argue against a simple loss of function effect. Previous work using ectopic overexpression of Gata3 in breast cancer cell lines that are ER and Gata3-negative, such as MDA-MB-231, has demonstrated the ability of ectopic Gata3 expression to suppress tumor and metastasis formation, although the relevance of manipulating Gata3 in an ER-negative, nonluminal cell type is uncertain [17-21, 29]. Moreover, some studies of Gata3 function have used MCF-7 cells but have not generally considered the fact that a GATA3 mutation is present in this cell line. Knockdown of Gata3 in MCF7 cells reduces both wild type and mutant proteins and therefore may not be a surrogate for the effects of GATA3 mutations. In this study, we have used gene editing to examine the functional consequences of a recurrent GATA3 truncating mutation in two ER+ breast cancer

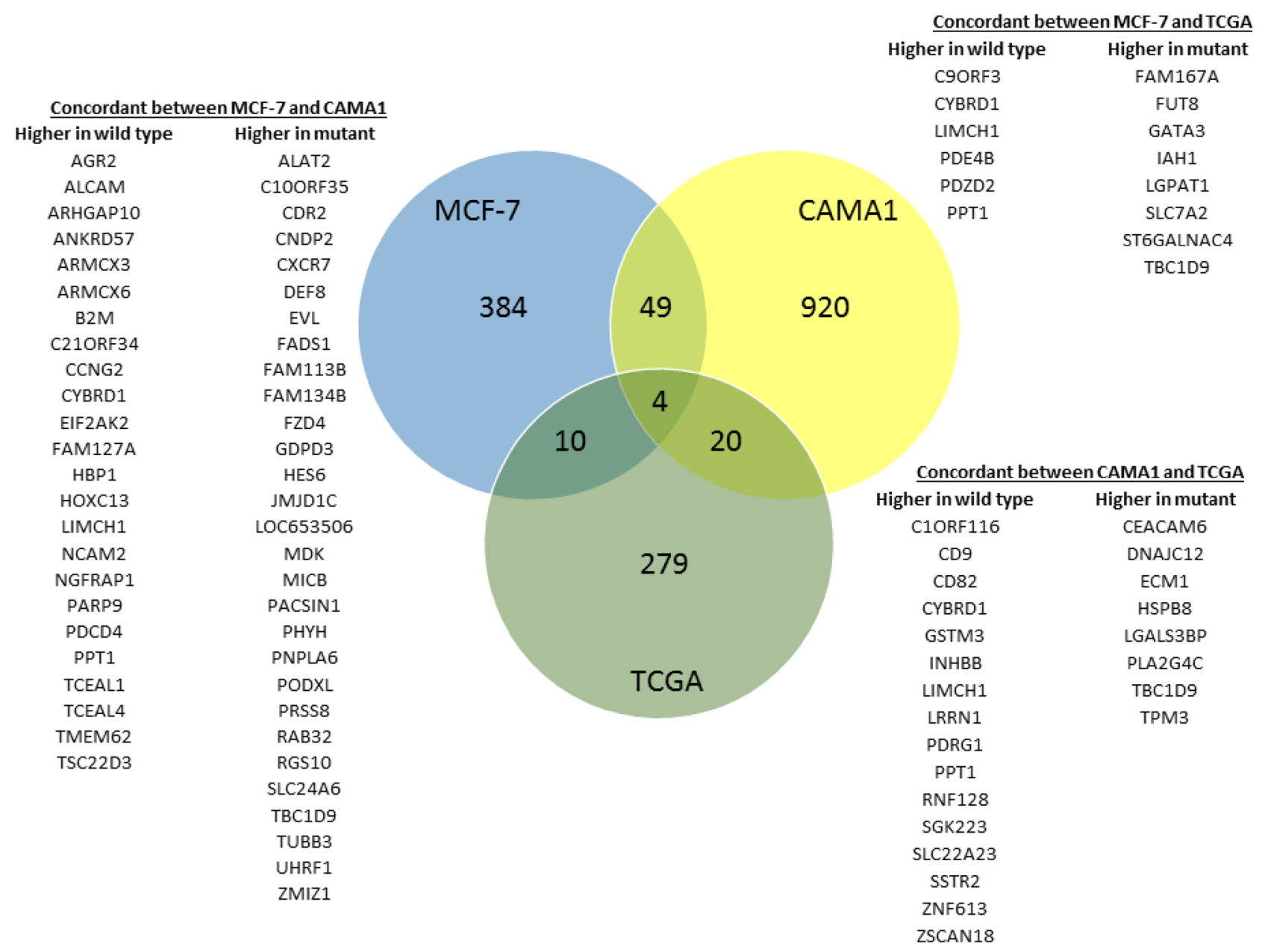

Figure 4: Differential gene expression related to $\boldsymbol{G A T A 3}$ mutation. Venn diagram showing overlap in differentially expressed genes in the isogenic MCF-7 and CAMA1 cell line panels and 594 ER + breast cancers from the TCGA dataset. Overlap between gene lists from MCF-7, CAMA1, and TCGA are all greater than expected by chance and statistically significant by hypergeometric probability $(P<$ 0.004 for MCF-7/TCGA, $P<0.007$ for CAMA1/TCGA, and $P<7 \times 10-11$ for MCF-7/CAMA1). 
cell lines, including MCF-7, where the mutation naturally occurs.

A caveat of our study is that we have modeled the effects of a specific ZF2 frameshift mutation. We and other investigators have noted that GATA3 mutations cluster in two protein regions: $\mathrm{ZF} 2$ and the $\mathrm{C}$-terminus. Whereas ZF2 mutations are truncating, many of the C-terminal mutations occur very close to the end of the protein and most of these shift into the same +1 reading frame to cause the addition of a neo-peptide sequence after the frameshift, resulting in a protein of higher predicted molecular weight $[3,30]$. It is less clear how C-terminal GATA3 mutations would impact protein function, but, as suggested by others, there could be distinct effects of these two mutation classes [30]. Our ability to model these C-terminal mutations in a MCF-7 GATA3 WT background may provide a more physiologic context to study their function.

The transcriptional effects of Gata3 are complex, as Gata3 has been documented to bind to thousands of sites in the genome and to be associated with multiple other transcription factors, including ER $\alpha$, TCF7L2, RARA, and FOXA1 [12, 19, 31, 32]. These relationships are also affected by feedback loops and transcriptional autoregulation [11]. In vitro evidence suggests that the ZF2 mutations in Gata3 are loss of function - at least at the level of DNA binding - although some CHIP-seq data show that DNA-binding-defective Gata3 mutants can still be recruited to a subset of genomic binding sites, perhaps through protein-protein interactions [3, $25,33]$. By using gene editing, we have simultaneously reduced dosage of a wild type allele when we have added a mutant allele, and vice-versa. This makes mechanistic separation of haploinsufficiency and gain-of-function effects difficult, although our approach faithfully models the effects of mutations that occur in human breast cancers. Our microarray data identifies a set of genes which are concordantly affected by GATA3 mutation in two ER+ breast cancer cell lines. We also observed concordant differential expression for a subset of these genes according to GATA3 mutation status in primary ER+ breast cancers from the TCGA dataset. We observed both upregulated and downregulated genes, consistent with both transcriptional activation and repression mediated by Gata3. Add-back of truncated mutant Gata3 recapitulated some of these transcriptional effects, consistent with at least a partial gain-of-function or dominant-negative effect.

The biological relevance of the genes affected by GATA3 mutation in our study will require further analysis, but several of them have plausible roles in breast cancer. CEACAM6 has been shown to be a marker of atypical ductal hyperplasia lesions at increased risk of progressing to invasive breast cancer, and its expression is highest in ER+ and Her2+ breast cancers [34, 35]. High CEACAM6 expression was associated with breast cancer recurrence following adjuvant tamoxifen, and knockdown of CEACAM6 restored tamoxifen sensitivity and reduced clonogenic growth, migration, and invasion of tamoxifen-resistant MCF-7 cells [36, 37]. PPT1 encodes a palmitoyl-protein thioesterase, which removes the post-translational modification palmitate from proteins, although the spectrum of its substrates is

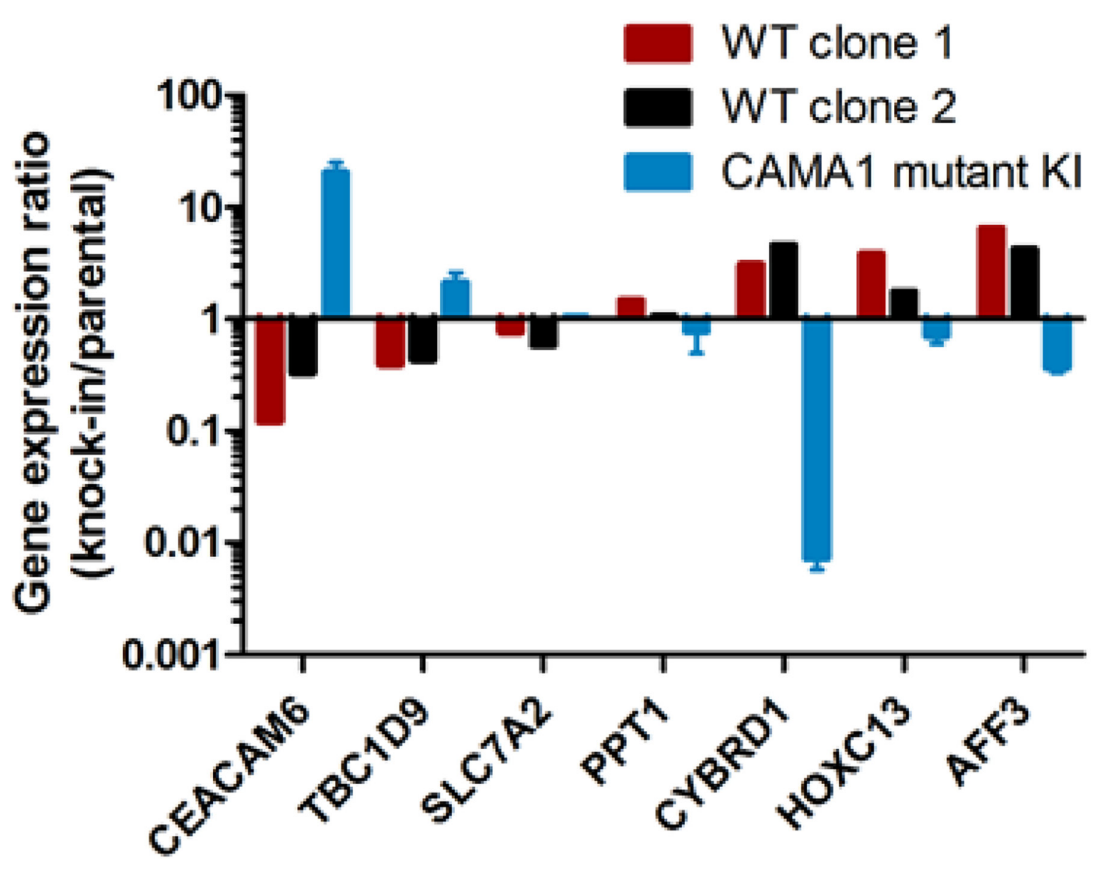

Figure 5: Gene expression changes effected by mutant Gata3. Quantitative RT-PCR for selected genes differentially expressed by microarray analysis. Gene expression for gene-edited clones is depicted as fold-change relative to the level in the parental cell line (X-axis). Bars are in opposing directions because GATA3 knock-in was wild type for MCF-7 and mutant for CAMA1. 
unknown. Intriguingly, palmitoylation of ER $\alpha$ has been shown to mediate its membrane localization and mitogenic function [38, 39]. Expression of TBC1D9, a Rab GTPase accelerating protein, is highly correlated with ER $\alpha$ and Gata3 expression in human breast cancers [40].

It is likely that GATA3 mutation affects developmental processes involving mammary cell lineage determination, which are sensitive to GATA3 dosage $[27,28,30,41,42]$. Mice with mammary gland-specific deletion of GATA3 have defective luminal differentiation $[27,28]$. A subset of Gata3 regulated genes may be critical for cell fate in the mammary gland, and dysregulation of transcription through GATA3 mutation may block terminal differentiation and start cells on the road to cancer. Hemizygous deletion of GATA3 in the mammary gland accelerates tumor formation in the PyMT model, and transgenic overexpression of wild type Gata3 delays tumor formation [41]. An early, developmental role for GATA3 mutation is not addressed by our cancer cell line model, but an early role does not necessarily preclude a later impact of these mutations on breast cancer phenotypes and outcomes. Nonetheless, we did not see significant effects on many of the previously reported Gata3 target genes in our isogenic cell line models. It is possible that a different subset of genes is affected by GATA3 mutation in luminal progenitor cells than in established breast cancer cells.

It has long been recognized that GATA3 mutations occur in the better-prognosis luminal subtypes of breast cancer. Recent data from the METABRIC project show improved breast cancer-specific survival for patients with ER+ tumors with GATA3 mutations, although this conclusion is not universally supported by mutation prevalence in metastatic breast cancer $[1,10,43]$. We sought to determine whether GATA3 mutation affects sensitivity to endocrine therapy or chemotherapy, but we did not find significant differences in response to tamoxifen, fulvestrant, paclitaxel, or doxorubicin in our MCF-7 cell line panel. GATA3 mutant MCF-7 cells did show an enhanced ability to form anchorage-independent colonies under estrogenfree conditions, but they were unable to grow as xenografts in non-estrogenized mice. Thus, GATA3 mutation does not cause the estrogen-independent phenotype of long term estrogen-deprived cells, which has been used as a model for aromatase inhibitor resistance. Our results are consistent with clinical trial results showing that GATA3 mutations did not impact response rates to neoadjuvant aromatase
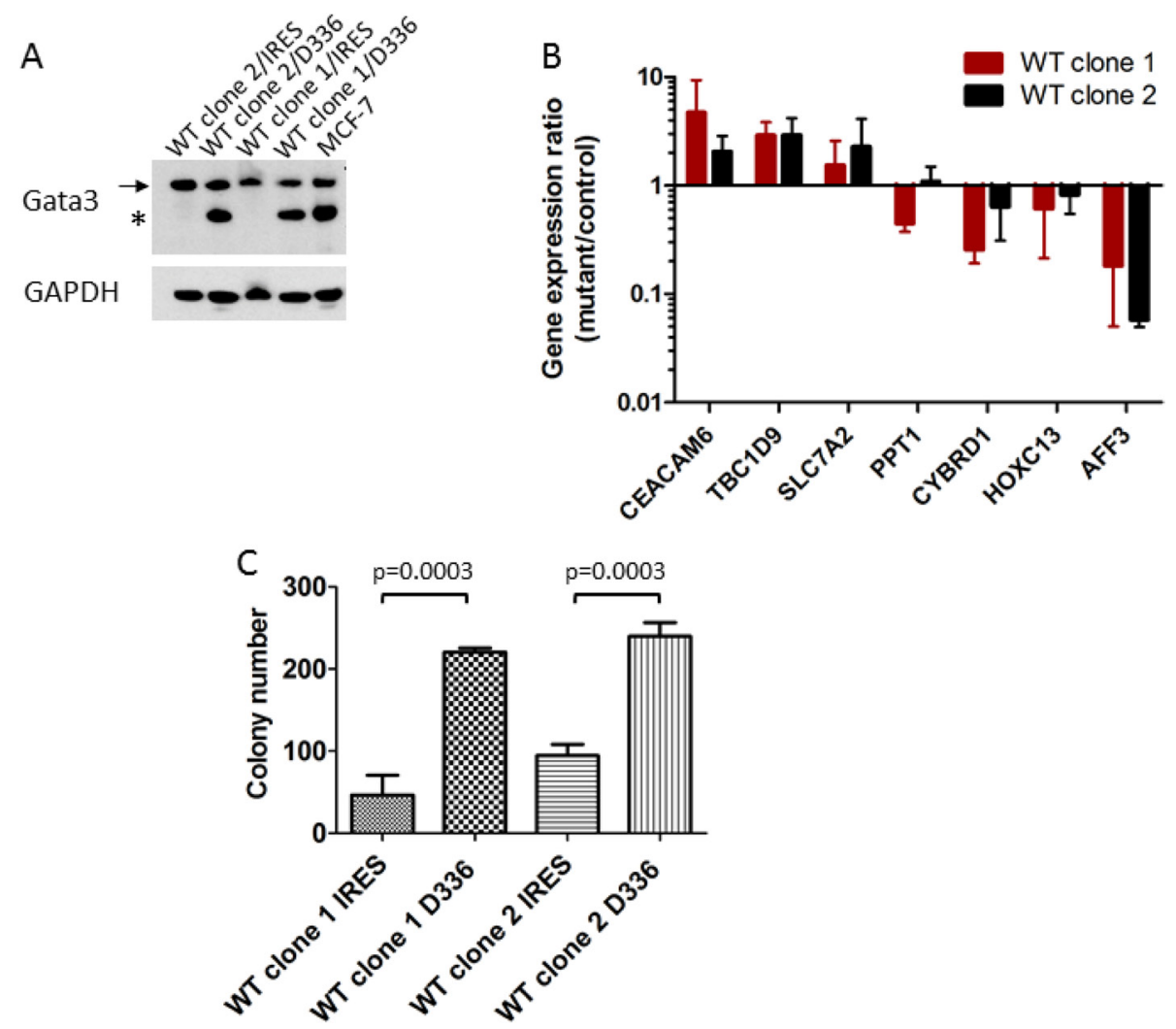

Figure 6: Add-back of mutant GATA3 supports a gain of function. (A) Re-expression of Gata3 D336Gfs*17 mutant protein in MCF-7-derived GATA3 wild type clones ("D336"). Western blot shows wild type (arrow) and mutant (asterisk) Gata3 proteins in transfected clones and MCF-7. (B) Quantitative RT-PCR for candidate Gata3 target genes. Gene expression ratio (fold change) for each clone is shown (D336Gfs*17 mutant/IRES vector control). Means and standard deviations from four experiments are shown. (C) Soft agar colony formation of MCF-7 derived GATA3 wild type clones transfected with vector (IRES) or GATA3 D336Gfs*17 mutant (D336). Means and standard deviations from three replicate wells are shown. $P=0.0003$ by $t$ test for difference between IRES and D336 for each clone. 
inhibitor therapy [44]. GATA3 WT MCF-7 and CAMA1 cells grew poorly as xenografts in immunocompromised mice compared to GATA3 mutant cells, however, raising the possibility that GATA3 mutant breast cancer cells do depend on the mutant protein for tumor growth in vivo. Whether this property can be attributed to specific genes regulated by Gata3 will require further study. Therefore, whether or not GATA3 mutant breast cancers have better clinical outcomes than ER+GATA3 wild type tumors, it remains possible that mutant Gata3 or its downstream effectors could be rational targets for breast cancer therapy.

\section{MATERIALS AND METHODS}

\section{Cell lines}

MCF-7 and CAMA1 cells were originally obtained from ATCC and the identity of the parental cell lines and the gene targeted derivatives was verified in October 2016 by STR analysis at the Johns Hopkins Genetic Resource Core Facility. Cells were maintained in DMEM (Cellgro) supplemented with $5 \%(\mathrm{MCF}-7)$ or $10 \%$ (CAMA1) FBS (Hyclone) and $100 \mathrm{U} / \mathrm{mL}$ penicillin and $100 \mu \mathrm{g} / \mathrm{mL}$ streptomycin (Cellgro). For growth assays the following media formulations were used: phenol-red free DMEM/ F12 (Invitrogen) with $0.5 \%$ charcoal-dextran treated FBS (Hyclone) with or without $1 \mathrm{nM} 17-\beta$-estradiol (Sigma). All cells were cultured at $37^{\circ} \mathrm{C}$ at $5 \% \mathrm{CO}_{2}$.

\section{Gene targeting at the $G A T A 3$ locus}

Gene targeting was conducted with recombinant adeno-associated viral (rAAV) vectors as described [24, 45, 46]. 5'- and 3'-homology arms were constructed by highfidelity PCR using genomic DNA (gDNA) from MCF10A as template for the homology arms. To correct the GATA3 c1006_1007insG mutation back to wild type, two rounds of gene targeting were employed. For the first round,
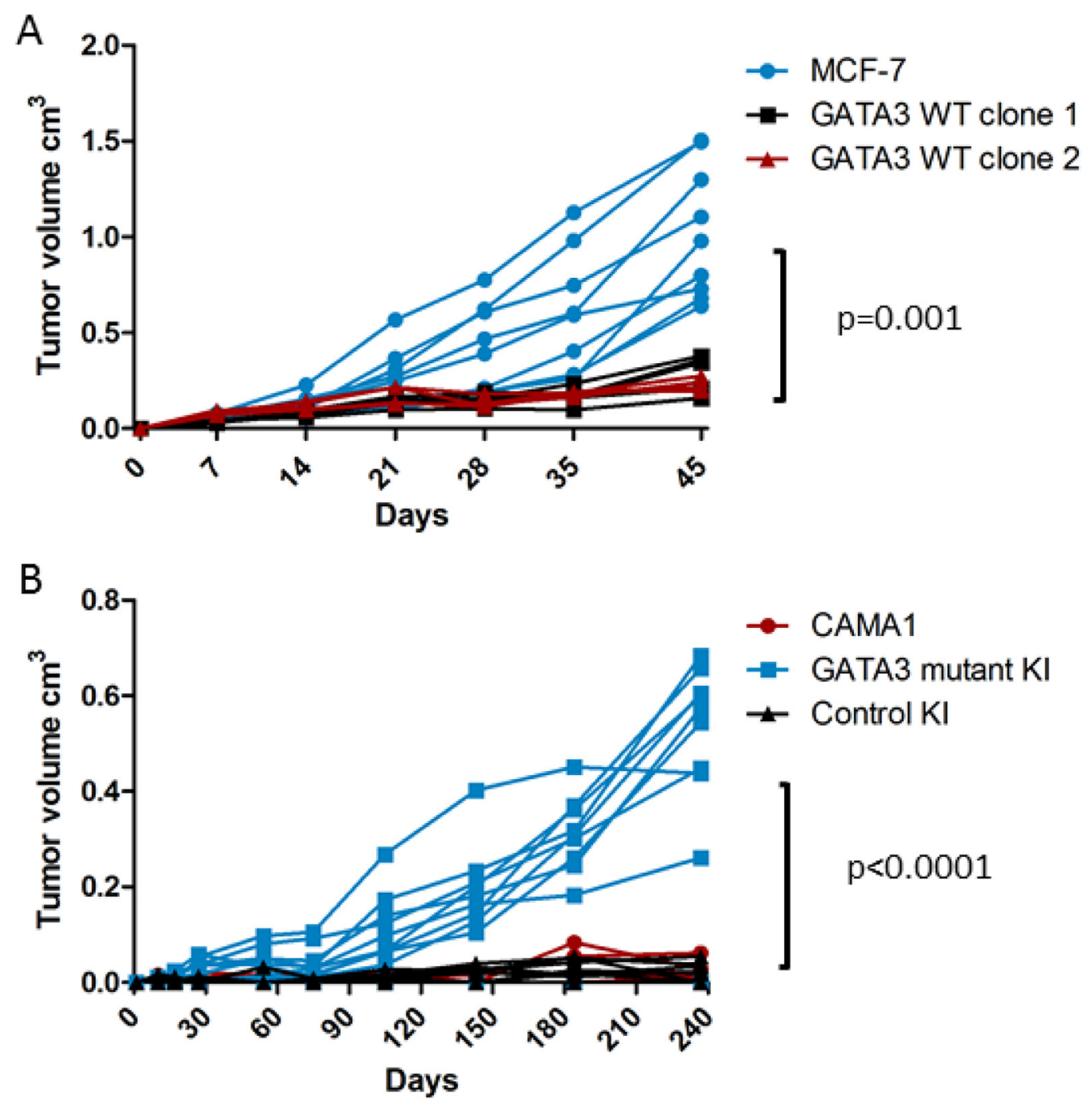

Figure 7: Xenograft growth of isogenic GATA3 mutant and wild type breast cancer cell lines. (A) Nude mouse xenograft growth of MCF-7 $(n=9)$ and GATA3 wild type derivative clones $(n=5$ each). $P$ value for repeated measures two-way ANOVA is shown. (B) NSG mouse xenograft growth of CAMA1, GATA3 mutant knock-in, and control knock-in cells $(n=10$ mice per group). $P$ value for repeated measures two-way ANOVA is shown. 
GATA3 exon 5 was included in the $5^{\prime}$ homology arm. Cells with one corrected GATA3 allele were then subjected to a second round of gene targeting using a different construct with the wild type exon 5 located in the 3 ' homology arm. CAMA1 cells were targeted as above using a construct with the GATA3 c1006 1007insG mutation in exon 5 in the 5 ' homology arm, which was generated by PCR using MCF-7 genomic DNA as a template. Primer sequences for PCR are available on request.

\section{DNA and RNA extraction, cDNA synthesis, PCR, and sequencing}

Genomic DNA and total RNA were prepared from cells using QIAamp DNA Blood kits and RNeasy kits (Qiagen), respectively. RNA was treated on-column with DNAaseI. CDNA was synthesized with First-Strand cDNA Synthesis kit (GE Biosciences). PCR amplification was done using GeneAmp 9700 (Applied Biosystems) and Phusion-HF (NEB) or Platinum Taq polymerase (Invitrogen). PCR primers to amplify cDNA were designed with forward and reverse primers located in distinct exons. Quantitative reverse transcriptase PCR was performed using SYBR green on a BioRad iCycler. Relative gene expression in triplicate wells was quantified using the $\Delta \Delta \mathrm{Ct}$ method with TATA binding protein (TBP) as a reference. Automated direct sequencing of PCR products was carried out by the Johns Hopkins DNA Synthesis and Sequencing Facility. Primer sequences for PCR and direct sequencing are available on request.

\section{Re-expression of mutant Gata3}

Full length cDNA encoding the Gata3 D336Gfs*17 protein was cloned into pIRESneo3 (Clontech). MCF-7 GATA3 WT clones were transfected with pIRESneo3 or pIRESneo3/Gata3 D336fs*17 using FuGENE 6 (Promega) and selected with G418 as stable pools.

\section{Soft agar colony formation}

$3 \times 10^{4}$ exponentially growing cells were cast in $3 \mathrm{~mL}$ of top layer medium composed of supplemented phenol red free DMEM/F12 and 0.4\% UltraPure agarose (Invitrogen) and poured on top of a $2 \mathrm{~mL}$ bottom layer containing $0.6 \%$ agarose in six-well tissue culture plates. Supplements consisted of $0.5 \%$ CD-FBS plus $1 \mathrm{nM} 17-\beta$-estradiol or $0.5 \%$ CD-FBS alone. Supplemented DMEM/F12 was added to the wells twice a week. Two independent experiments were done in triplicate. Colonies were fixed and stained with $0.05 \%$ crystal violet in $10 \%$ ethanol. For the experiment in Figure 2, stained plates were scanned and macroscopically visible colonies were counted using ImageJ. For the experiment in Figure 6, media condition was $0.5 \%$ CD-FBS without estrogen. Four images of each well were captured using a dissecting microscope at $10 \mathrm{X}$ magnification, and colonies with pixel size $>200$ were quantified using ImageJ and averaged for each well. Triplicate wells for each sample were then averaged.

\section{Drug treatment experiments}

Cells were plated in triplicate wells. For experiments using 4-hydroxy tamoxifen and fulvestrant, cells were cultured in medium with $1 \mathrm{nM} 17-\beta$-estradiol as described above. Other experiments were conducted in DMEM/5\% FBS medium. Drugs were added on day 1 . Cells were harvested and Trypan blue-excluding cells were counted on the indicated days. Viable cell numbers were normalized to day 1 values for each sample. Viability versus log of the drug concentration was plotted and fit with a non-linear regression model with variable slope to calculate IC $^{50}$ values using GraphPad Prism 5. For each drug, curves for MCF-7 were compared with curves for the average of the two GATA3 wild type clones using extra sum-of-squares $\mathrm{F}$ test. The $p$ value threshold of 0.05 was adjusted for multiple comparisons.

\section{Immunoblotting}

Whole-cell protein extracts prepared in Laemmli sample buffer were resolved by SDS-PAGE using NuPage gels (Invitrogen), transferred to Invitrolon polyvinylidene difluoride membranes (Invitrogen), and probed with primary and horseradish peroxidase-conjugated secondary antibodies. Primary antibodies were anti-Gata3 mouse monoclonal antibody (Sc-269, Santa Cruz Biotechnology), anti-ER $\alpha$ mouse monoclonal antibody (Beckman Coulter), and anti-glyceraldehyde-3-phosphate dehydrogenase (GAPDH) mouse monoclonal antibody (6C5; Abcam). Blots were exposed to Kodak XAR film using chemiluminescence for detection (Perkin Elmer).

\section{Xenograft experiments}

All experiments were conducted under a protocol approved by the institutional animal care and use committee and followed the National Institutes of Health Guide for the Care and Use of Laboratory Animals. For experiments with MCF-7 and its derivatives, 8- to 10-week-old female athymic nude mice (Taconic) were used. Two days prior to cell inoculation, mice were surgically implanted with slowrelease $17-\beta$-estradiol pellets. For each group, five (each GATA3 WT clone) or nine (MCF-7) mice were injected subcutaneously the flank with $200 \mu \mathrm{l}$ mixture containing $1 \times 10^{6}$ cells in $20 \%$ PBS and $80 \%$ Matrigel. For CAMA1 cells, NSG mice were injected in the mammary fat pad with $2 \times 10^{6}$ cells in $20 \%$ PBS and 80\% Matrigel, 10 mice per group. After the appearance of palpable tumors, tumors were measured with the frequency shown and volumes were calculated by multiplying length, width, and height for each individual tumor. 


\section{Microarray gene expression analysis}

All cell lines were cultured in $0.5 \%$ CD-FBS medium without estrogen prior to RNA harvest. Three separate microarray hybridizations were run, comprising a total of four biological replicates of parental MCF-7 cells, five biological replicates of MCF-7 GATA3 wild type clone 1, and two biological replicates of MCF-7 GATA3 wild type clone 2. Single samples from parental CAMA1 and GATA3 mutant knock-in CAMA1 cells were hybridized. Sample quality assessment and microarray analysis using HumanHT-12 v4 Expression BeadChip arrays (Illumina, San Diego, CA) were performed at the Sidney Kimmel Comprehensive Cancer Center Microarray Core Facility at Johns Hopkins University, Baltimore. $500 \mathrm{ng}$ total RNA from each sample was amplified and labeled using the Illumina TotalPrep RNA Amplification Kit (AMIL1791, Ambion, Austin, TX) as described in the instruction manual. $750 \mathrm{ng}$ biotin-labeled cRNA was combined with hybridization buffer and hybridized to the array at $58^{\circ} \mathrm{C}$ for $16-20$ hours. After hybridization, the hybridization cartridge was disassembled and the array was washed with buffer at $55^{\circ} \mathrm{C}$ and blocked at room temperature. Bound biotinylated cRNA was stained with streptavidin-Cy3 and then washed. Dried arrays were stored in a dark box until scanned with iScan System. Data were extracted with Gene Expression Module in GenomeStudio Software. Quantile normalization across all arrays was performed using the lumi package in R, and differential gene expression in MCF-7 was calculated with the $\mathrm{R}$ package limma using a Benjamini-Hochberg adjusted $p$ value of $<0.05$. Differential gene expression between CAMA1 parental and mutant knock-in clones was performed using BRB-ArrayTools v4.2 with a fold-change cut-off of 1.25 [47]. Raw and normalized gene expression data have been submitted to the NCBI Gene Expression Omnibus under accession number GSE101780.

\section{TCGA RNAseq analysis}

TCGA breast cancer data was analyzed using CBioPortal [48]. 594 ER+ cases with RNAseq data were divided into two groups based on presence ( 86 cases) or absence (508 cases) of GATA3 mutations. Differentially expressed transcripts were identified with a BenjaminiHochberg $q$ value $<0.01$. Gene list overlap significance testing was carried out using hypergeometric probability test.

\section{Statistical analysis}

Cell proliferation assays and xenograft growth experiments were compared using repeated measures two-way ANOVA with Bonferroni adjustment for multiple comparisons. Colony formation was compared using unpaired $t$ tests. All analyses were conducted using GraphPad Prism 5 software.

\section{Author contributions}

J.L. and J.P.G. conceived the project and designed the experiments. J.L., J.P.G., M.F., M.T., D.M.R. and J.M. performed experiments and analyzed data. R.B.S. and J.L. analyzed microarray data. All authors wrote, edited, and approved the manuscript.

\section{CONFLICTS OF INTEREST}

Under a licensing agreement between Horizon Discovery, Ltd. and the Johns Hopkins University, Drs. Lauring and Gustin may be entitled to royalties on cell lines described in this article. This arrangement has been reviewed and approved by the Johns Hopkins University in accordance with its conflict of interest policies. The other authors declare no conflict of interest.

\section{FUNDING}

This work was supported by NIH P30 CA006973 and the Avon Foundation (J.L.).

\section{REFERENCES}

1. Pereira B, Chin SF, Rueda OM, Vollan HK, Provenzano E, Bardwell HA, Pugh M, Jones L, Russell R, Sammut SJ, Tsui DW, Liu B, Dawson SJ, et al. The somatic mutation profiles of 2,433 breast cancers refines their genomic and transcriptomic landscapes. Nature Comm. 2016; 7:11479.

2. Ciriello G, Gatza ML, Beck AH, Wilkerson MD, Rhie SK, Pastore A, Zhang H, McLellan M, Yau C, Kandoth C, Bowlby R, Shen H, Hayat S, et al. Comprehensive Molecular Portraits of Invasive Lobular Breast Cancer. Cell. 2015; 163:506-519.

3. Gaynor KU, Grigorieva IV, Allen MD, Esapa CT, Head RA, Gopinath P, Christie PT, Nesbit MA, Jones JL, Thakker RV. GATA3 mutations found in breast cancers may be associated with aberrant nuclear localization, reduced transactivation and cell invasiveness. Horm Cancer. 2013; 4:123-139.

4. Usary J, Llaca V, Karaca G, Presswala S, Karaca M, He X, Langerod A, Karesen R, Oh DS, Dressler LG, Lonning PE, Strausberg RL, Chanock S, et al. Mutation of GATA3 in human breast tumors. Oncogene. 2004; 23:7669-7678.

5. Fang SH, Chen Y, Weigel RJ. GATA-3 as a marker of hormone response in breast cancer. J Surg Res. 2009; 157:290-295.

6. Mehra R, Varambally S, Ding L, Shen R, Sabel MS, Ghosh D, Chinnaiyan AM, Kleer CG. Identification of GATA3 as a breast cancer prognostic marker by global gene expression meta-analysis. Cancer Res. 2005; 65:11259-11264.

7. Parikh P, Palazzo JP, Rose LJ, Daskalakis C, Weigel RJ. GATA-3 expression as a predictor of hormone response in breast cancer. J Am Coll Surg. 2005; 200:705-710. 
8. Voduc D, Cheang M, Nielsen T. GATA-3 expression in breast cancer has a strong association with estrogen receptor but lacks independent prognostic value. Cancer Epidemiol Biomarkers Prev. 2008; 17:365-373.

9. Hoch RV, Thompson DA, Baker RJ, Weigel RJ. GATA-3 is expressed in association with estrogen receptor in breast cancer. Int J Cancer. 1999; 84:122-128.

10. Lefebvre C, Bachelot T, Filleron T, Pedrero M, Campone M, Soria JC, Massard C, Levy C, Arnedos M, Lacroix-Triki M, Garrabey J, Boursin Y, Deloger M, et al. Mutational Profile of Metastatic Breast Cancers: A Retrospective Analysis. PLoS Med. 2016; 13:e1002201.

11. Eeckhoute J, Keeton EK, Lupien M, Krum SA, Carroll JS, Brown M. Positive cross-regulatory loop ties GATA-3 to estrogen receptor alpha expression in breast cancer. Cancer Res. 2007; 67:6477-6483.

12. Theodorou V, Stark R, Menon S, Carroll JS. GATA3 acts upstream of FOXA1 in mediating ESR1 binding by shaping enhancer accessibility. Genome Res. 2013; 23:12-22.

13. Oh DS, Troester MA, Usary J, Hu Z, He X, Fan C, Wu J, Carey LA, Perou CM. Estrogen-regulated genes predict survival in hormone receptor-positive breast cancers. J Clin Oncol. 2006; 24:1656-1664.

14. Pei XH, Bai F, Smith MD, Usary J, Fan C, Pai SY, Ho IC, Perou CM, Xiong Y. CDK inhibitor p18(INK4c) is a downstream target of GATA3 and restrains mammary luminal progenitor cell proliferation and tumorigenesis. Cancer Cell. 2009; 15:389-401.

15. Abba MC, Nunez MI, Colussi AG, Croce MV, Segal-Eiras A, Aldaz CM. GATA3 protein as a MUC1 transcriptional regulator in breast cancer cells. Breast Cancer Res. 2006; 8:R64.

16. Molenaar JJ, Ebus ME, Koster J, Santo E, Geerts D, Versteeg R, Caron HN. Cyclin D1 is a direct transcriptional target of GATA3 in neuroblastoma tumor cells. Oncogene. 29:2739-2745.

17. Chu IM, Lai WC, Aprelikova O, El Touny LH, KourosMehr H, Green JE. Expression of GATA3 in MDAMB-231 triple-negative breast cancer cells induces a growth inhibitory response to TGFss. PLoS One. 2013; 8:e61125.

18. Chu IM, Michalowski AM, Hoenerhoff M, Szauter KM, Luger D, Sato M, Flanders K, Oshima A, Csiszar K, Green JE. GATA3 inhibits lysyl oxidase-mediated metastases of human basal triple-negative breast cancer cells. Oncogene. 2012; 31:2017-2027.

19. Kong SL, Li G, Loh SL, Sung WK, Liu ET. Cellular reprogramming by the conjoint action of ERalpha, FOXA1, and GATA3 to a ligand-inducible growth state. Mol Syst Biol. 2011; 7:526.

20. Si W, Huang W, Zheng Y, Yang Y, Liu X, Shan L, Zhou X, Wang Y, Su D, Gao J, Yan R, Han X, Li W, et al. Dysfunction of the Reciprocal Feedback Loop between GATA3- and ZEB2-Nucleated Repression Programs Contributes to Breast Cancer Metastasis. Cancer Cell. 2015; 27:822-836.
21. Yan W, Cao QJ, Arenas RB, Bentley B, Shao R. GATA3 inhibits breast cancer metastasis through the reversal of epithelial-mesenchymal transition. J Biol Chem. 2010; 285:14042-14051.

22. Karakas B, Weeraratna AT, Abukhdeir AM, Konishi H, Gustin JP, Vitolo MI, Bachman KE, Park BH. p21 Gene knock Down Does Not Identify Genetic Effectors Seen with Gene Knock Out. Cancer Biol Ther. 2007; 6:1025-1030.

23. Konishi H, Karakas B, Abukhdeir AM, Lauring J, Gustin JP, Garay JP, Konishi Y, Gallmeier E, Bachman KE, Park $\mathrm{BH}$. Knock-in of mutant K-ras in nontumorigenic human epithelial cells as a new model for studying K-ras mediated transformation. Cancer Res. 2007; 67:8460-8467.

24. Lauring J, Cosgrove DP, Fontana S, Gustin JP, Konishi H, Abukhdeir AM, Garay JP, Mohseni M, Wang GM, Higgins MJ, Gorkin D, Reis M, Vogelstein B, et al. Knock in of the AKT1 E17K mutation in human breast epithelial cells does not recapitulate oncogenic PIK3CA mutations. Oncogene. 2010; 29:2337-2345.

25. Adomas AB, Grimm SA, Malone C, Takaku M, Sims JK, Wade PA. Breast tumor specific mutation in GATA3 affects physiological mechanisms regulating transcription factor turnover. BMC Cancer. 2014; 14:278.

26. Kavallaris M. Microtubules and resistance to tubulinbinding agents. Nat Rev Cancer. 2010; 10:194-204.

27. Kouros-Mehr H, Slorach EM, Sternlicht MD, Werb Z. GATA-3 maintains the differentiation of the luminal cell fate in the mammary gland. Cell. 2006; 127:1041-1055.

28. Asselin-Labat ML, Sutherland KD, Barker H, Thomas R, Shackleton M, Forrest NC, Hartley L, Robb L, Grosveld FG, van der Wees J, Lindeman GJ, Visvader JE. Gata-3 is an essential regulator of mammary-gland morphogenesis and luminal-cell differentiation. Nat Cell Biol. 2007; 9:201209.

29. Takaku M, Grimm SA, Shimbo T, Perera L, Menafra R, Stunnenberg HG, Archer TK, Machida S, Kurumizaka $\mathrm{H}$, Wade PA. GATA3-dependent cellular reprogramming requires activation-domain dependent recruitment of a chromatin remodeler. Genome Biol. 2016; 17:36.

30. Mair B, Konopka T, Kerzendorfer C, Sleiman K, Salic S, Serra V, Muellner MK, Theodorou V, Nijman SM. Gainand Loss-of-Function Mutations in the Breast Cancer Gene GATA3 Result in Differential Drug Sensitivity. PLoS Genet. 2016; 12:e1006279.

31. Frietze S, Wang R, Yao L, Tak YG, Ye Z, Gaddis M, Witt H, Farnham PJ, Jin VX. Cell type-specific binding patterns reveal that TCF7L2 can be tethered to the genome by association with GATA3. Genome Biol. 2012; 13:R52.

32. Hua S, Kittler R, White KP. Genomic antagonism between retinoic acid and estrogen signaling in breast cancer. Cell. 2009; 137:1259-1271.

33. Liu Z, Merkurjev D, Yang F, Li W, Oh S, Friedman MJ, Song X, Zhang F, Ma Q, Ohgi KA, Krones A, Rosenfeld MG. Enhancer activation requires trans-recruitment 
of a mega transcription factor complex. Cell. 2014; 159:358-373.

34. Balk-Moller E, Kim J, Hopkinson B, TimmermansWielenga V, Petersen OW, Villadsen R. A marker of endocrine receptor-positive cells, CEACAM6, is shared by two major classes of breast cancer: luminal and HER2enriched. Am J Pathol. 2014; 184:1198-1208.

35. Poola I, Shokrani B, Bhatnagar R, DeWitty RL, Yue Q, Bonney G. Expression of carcinoembryonic antigen cell adhesion molecule 6 oncoprotein in atypical ductal hyperplastic tissues is associated with the development of invasive breast cancer. Clin Cancer Res. 2006; 12:47734783.

36. Lewis-Wambi JS, Cunliffe HE, Kim HR, Willis AL, Jordan VC. Overexpression of CEACAM6 promotes migration and invasion of oestrogen-deprived breast cancer cells. Eur J Cancer. 2008; 44:1770-1779.

37. Maraqa L, Cummings M, Peter MB, Shaaban AM, Horgan K, Hanby AM, Speirs V. Carcinoembryonic antigen cell adhesion molecule 6 predicts breast cancer recurrence following adjuvant tamoxifen. Clin Cancer Res. 2008; 14:405-411.

38. La Rosa P, Pesiri V, Leclercq G, Marino M, Acconcia F. Palmitoylation regulates 17beta-estradiol-induced estrogen receptor-alpha degradation and transcriptional activity. Mol Endocrinol. 2012; 26:762-774.

39. Pedram A, Razandi M, Lewis M, Hammes S, Levin ER. Membrane-localized estrogen receptor alpha is required for normal organ development and function. Dev Cell. 2014; 29:482-490.

40. Andres SA, Wittliff JL. Co-expression of genes with estrogen receptor-alpha and progesterone receptor in human breast carcinoma tissue. Hor Mol Biol Clin Investig. 2012; 12:377-390.

41. Asselin-Labat ML, Sutherland KD, Vaillant F, Gyorki DE, Wu D, Holroyd S, Breslin K, Ward T, Shi W, Bath ML, Deb $\mathrm{S}$, Fox SB, Smyth GK, et al. Gata-3 negatively regulates the tumor-initiating capacity of mammary luminal progenitor cells and targets the putative tumor suppressor caspase-14. Mol Cell Biol. 2011; 31:4609-4622.

42. Kouros-Mehr H, Bechis SK, Slorach EM, Littlepage LE, Egeblad M, Ewald AJ, Pai SY, Ho IC, Werb Z. GATA-3 links tumor differentiation and dissemination in a luminal breast cancer model. Cancer Cell. 2008; 13:141-152.

43. Liu J, Prager-van der Smissen WJ, Look MP, Sieuwerts AM, Smid M, Meijer-van Gelder ME, Foekens JA, Hollestelle A, Martens JW. GATA3 mRNA expression, but not mutation, associates with longer progression-free survival in ER-positive breast cancer patients treated with first-line tamoxifen for recurrent disease. Cancer Lett. 2016; 376:104-109.

44. Ellis MJ, Ding L, Shen D, Luo J, Suman VJ, Wallis JW, Van Tine BA, Hoog J, Goiffon RJ, Goldstein TC, Ng S, Lin L, Crowder R, et al. Whole-genome analysis informs breast cancer response to aromatase inhibition. Nature. 2012; 486:353-360.

45. Beaver JA, Gustin JP, Yi KH, Rajpurohit A, Thomas M, Gilbert SF, Rosen DM, Ho Park B, Lauring J. PIK3CA, AKT1 Mutations Have Distinct Effects on Sensitivity to Targeted Pathway Inhibitors in an Isogenic Luminal Breast Cancer Model System. Clin Cancer Res. 2013; 19:5413-5422.

46. Konishi H, Lauring J, Garay JP, Karakas B, Abukhdeir AM, Gustin JP, Konishi Y, Park BH. A PCR-based highthroughput screen with multiround sample pooling: application to somatic cell gene targeting. Nat Protoc. 2007; 2:2865-2874.

47. Simon R, Lam A, Li MC, Ngan M, Menenzes S, Zhao Y. Analysis of gene expression data using BRB-ArrayTools. Cancer Inform. 2007; 3:11-17.

48. Cerami E, Gao J, Dogrusoz U, Gross BE, Sumer SO, Aksoy BA, Jacobsen A, Byrne CJ, Heuer ML, Larsson E, Antipin Y, Reva B, Goldberg AP, et al. The cBio cancer genomics portal: an open platform for exploring multidimensional cancer genomics data. Cancer Discov. 2012; 2:401-404. 